\title{
The Discussion on the System of Cross-subsidization for Large User Direct Power-Purchase in Electricity Market
}

\author{
Zhou Long ${ }^{1}$, Liu Dunnan ${ }^{2}$, Cai Hui ${ }^{3}$,Tang Tianqii ${ }^{4, *}$ \\ ${ }^{1}$ Guangdong Power Grid Corporation, Guangzhou, Guangdong province China \\ ${ }^{2}$ North China Electric Power University, Beijing, China
}

\begin{abstract}
With the deepening of the reform of the electric power system in China, the system of Cross-subsidization for large users' direct power-purchase has achieved initial results. The domestic experimental work of large users direct Power-Purchase and the practice of foreign countries have demonstrated that " Large users direct power-purchase " is advantageous to construct the multi buyer - seller's market competition pattern, the construction of the competitive market and to speed up the construction of competitive market; "Large users direct Power-Purchase " is also help price to play a guiding role for the supply and demand of the market, which would timely reflect the real needs of the market. However, the experimental work revealed some urgent problems with the System of Cross-subsidization. Under this background, this paper deeply studies the key problems of the provincial Cross-subsidization for the large user's direct power-purchase. The research results of this paper can improve the implementation scheme of the large user's direct power-purchase and supporting mechanism. It also can further promote and ensure the implementation of the direct power-purchase laid the foundation to establish the competitive power market and realize the optimal allocation of power resources.
\end{abstract}

\section{Introduction}

As an important breakthrough in the deepening reform of electric power system, large user's direct power-purchase plays a key role in the process of building the electricity market. Electric power user's direct trading mechanism is to refer to, not to change the current power grid system, but to accelerate the opening of large users and power generation companies' direct power-purchase. Let the above scale users and power companies to establish a market trading mechanism. Users can trade power with generate electricity companies directly, who is certain voltage level or with power above the level, and pay charges to grid companies. This way has been adopted in many countries, international experience has proved that the method is relatively simple, safe, effective, and it is fit for our national conditions. In 2009, National Development and Reform Commission promulgated the relevant norms, in order to regulate and further promote the experimental work of the large user's direct power-purchase, the pilot areas' transmission and distribution price in the two part of the system, which is comments by the provincial department in charge of price and approval by the national development and Reform Commission.

However, the large user's direct power-purchase will cause the adjustment of interest pattern, which is one of the key issues that need to be solved in the process of promoting the large user's direct power-purchase. Therefore, it is necessary to study the mechanism of cross-subsidization in the large user's direct powerpurchase mode and avoid the disputes and adverse effects caused by the transfer of government cross-subsidization to other power users.

\section{The formation mechanism of transmission and distribution under the large user's direct power-purchase}

In the process of large user's direct power-purchase, large users and power generation companies to achieve a large amount of electricity, power equipment capacity, the use of power transmission and distribution grid is relatively high, in order to reasonably compensate for the Power Grid Corp's transmission costs, improve equipment utilization efficiency, proposed the implementation of the two power transmission price to carry out large user's direct power-purchase.

Capacity cost of transmission and distribution reflect the fixed cost of transmission and distribution. Electricity costs reflect the variable cost. Therefore, through reasonably allocated the fixed cost and variable cost of the transmission and distribution to each user can determine the two part of the large user's direct powerpurchase transmission and distribution price.

1) The selection of fixed cost allocation model

In the long-term planning of power system, annual investment situation is not the same. It may have a peak of investment. Once the new power plant is put into operation, the fixed cost well increases rapidly. After the load growth, the rapid decline. In such a long-term marginal cost to develop the price, the price will be a big difference between the years. This is because marginal cost pricing does not have to be shared equally among the each year. Therefore, if the marginal cost method is used to calculate the transmission and distribution price, the price will be changed every year and there is a big difference between the price and the actual price. But for the comprehensive cost method based on the accounting, the financial balance is first, and then considers the cost allocation. From the marginal cost pricing's principle of economic efficiency, financial balance is a constraint condition. Under the present stage of China's electric power market, the comprehensive cost method is easy to 
be understood and accepted by the public, the operation is strong, and the process is clear and easy to supervise. Combined with the actual situation of the large user's direct power-purchase, the comprehensive cost method is suggested to calculate the transmission and distribution cost.

Through analysis and comparison of various methods contained in comprehensive cost method, it can be found:

a. Contract path method is required to determine the path of the Power Flow in advance, not suitable for largescale power grid pricing

b. Boundary power flow method is used to calculate the transmission cost, which is generally used to calculate the transmission cost and the power changes on the boundary tie line, it is not used for the regional transmission and distribution pricing;

c. The MW-Miles method is very similar to Line-byLine method. The difference is only in the Line-by-Line method's calculation of the influence of the transmission and distribution services on the power flow of the transmission and distribution network at a certain load level. While the MW - km method is assumed to be the whole network only to calculate the transaction, on this basis, the impact of the transaction on the grid. Calculation of complex and more suitable for real-time transmission and distribution price calculation;

2) The selection of change cost allocation model

In the cost of change, the maintenance cost of the operation and maintenance, in addition to the net loss, is shared by the marginal cost method to direct powerpurchase large users. This is because the marginal cost method can reflect the real situation of the resources, it is advantageous to optimize the allocation of resources, and it is superior to the accounting cost method in the financial balance; At the same time, due to the transmission process of the power grid, the operation and maintenance costs account for a very small proportion of the total transmission cost, so the marginal cost method is used to share the operation and maintenance costs will not be a big change in the price of each year.

The relevant suggestions for the calculation and allocation method of net loss: The cost of the net loss on the special transmission line is all bore by the large users; the marginal loss coefficient method can play a more important role in optimizing the allocation of grid resources and improving the efficiency. For the Public transmission network loss, it is suggested that the cost of the network is shared by the marginal loss coefficient method.

In the period when the user's option is not fully released, with a simple, actionable principle and the condition of the large user access, the blocking of transactions for direct purchase is not allowed. And in the case of reasonable power grid, the general will not appear blocked.

\section{Cross-subsidization share mechanism and management method}

Large user direct transaction will cause the adjustment of interest pattern, which is one of the key issues that need to be solved in the process of promoting the large user's direct power-purchase. Therefore, it is necessary to study the mechanism of cross-subsidization in the large user's direct power-purchase mode and avoid the disputes and adverse effects caused by the transfer of government cross-subsidization to other power users.

China's current electricity sales price is approved by the government price authorities. To approve the price level not only to considering the user's power supply cost, but also to consider the power of universal service responsibilities, service macroeconomic regulation and industrial structure adjustment policies and other social functions. Power monopoly enterprises, as the executive of electric power universal service, assume the obligation to provide universal service, the enterprise is not only in the profitable areas (developed area or industry, business users) to provide power services, but also in the nonprofitable areas (high cost areas or rural, low-income users) to provide services, so will cause the policy of universal service loss. In our country, we make up for the loss above-mentioned from the Excess revenue in the profitable areas. Therefore, it caused the phenomenon that the price level deviation from the actual cost .That is to say, the electricity price for partial electric power users is lower than the cost of the electricity supply. At the same time through the other power users to receive a higher price of to compensate for the above losses, which is called cross-subsidization for the sale price.

Through the implementation of the crosssubsidization, to solve the two aspects of the problem: first, the cross-subsidization mechanism to ensure that low-income residents to enjoy low-cost daily basic electricity; second, power companies can use crosssubsidization mechanism to raise funds for the construction of power grid.

At present, China's cross-subsidization for the sale price mainly reflected in the following aspects:

1)TOU Power Price. Such as TOU power price will caused cross-subsidization between Valley-load price and Peck-load price.

2)Cross subsidy between different voltage levels.

3)Subsidies between power generation and user.

4)Between different regions, the general phenomenon is the economically developed regions subsidize to the backward areas.

5)Cross-subsidization between different types of users. Mainly for large industrial, general industrial subsidize to residents.

At present, in the process of the pilot work of the large user's direct power-purchase, various pilot implementation plan are not mentioned large users should bear the cost of electricity in a certain extent for residents and agricultural cross subsidies, and it is not clear whether to continue the cross-subsidization policies, approved and charged cross-subsidization cost and how to compensate for the loss caused by the power grid companies to provide universal service. Although various pilot implementation plan are provided that levy a portion of the government funds and additional from the sales price of large users and power generation companies direct power-purchase. 


\section{Cross-subsidization mechanism for large user's direct power-purchase}

This part is based on the analysis of the basic factors that need to be taken into account and pay attention to the calculation of cross-subsidization. Put forward suggestions about how to charge large user's crosssubsidization.

(1) Factors should be considered when calculating cross-subsidization

In order to clear the situation about power sales price of cross-subsidization and determine the standard for the cost of cross-subsidization, the following factors should be considered in the process of setting up the crosssubsidization price:

1) Provinces (regions) in recent years, the weighted average directory power price level of sales price. The electricity and the weighted average catalog price level of all kinds of electricity consumption in the different voltage levels. The theoretical average catalog sales price level which is calculating in line with the provisions of the national electricity price policy.

2) The actual implemented weighted average price level of the sales price in the provinces (regions) in recent years; the actual electricity price v the electricity and the weighted average directory price level of all kinds of electricity consumption in the different voltage levels. The price difference between the actual price and the national prescriptive catalog price, and the specific reasons for the price difference.

3) The specific circumstances and the analysis results of the provinces (regions) sales price cross-subsidization, including: (1) The situation of various types of electric torso' s-subsidization based on national prescriptive catalog price and electricity sales in recent years.(2)The cross-subsidization situation of various types of electric industry (mainly refers to the large industry). The situation of cross-subsidization between the same electricity and different voltage levels industries.

(2) The charge mode of large user's direct powerpurchase cross-subsidization

In consideration of the characteristics of our country's national conditions, in the short term, the complete abolition of cross subsidy is not realistic, and cross subsidy will be in a certain period of time and the longterm existence. Therefore, we should reduce crosssubsidization gradually, and abolish subsidies when conditions are ripe.

In the process of large user's direct power-purchase, suggested by the following three modes to charge crosssubsidization cost:

1) Through the way of a surcharge on large power users, set up special funds to implement the charge of crossing subsidies. For all power market large power users to levy a universal service fund, which provides all of the large users of direct power-purchase with power companies should pay the fund, and then by the electricity regulatory authorities subsidies the funds to the Power Grid Corp, to achieve cross subsidies.

Governments should determine a reasonable power universal service fund scale, so as to compensate for the loss caused by the implementation of large user direct power-purchase. The calculation method of the fund is proposed as follows:

The influence of large user direct power-purchase on the benefit of power grid enterprises_ $L_{P}$

$$
L_{P}=R_{H}-R_{L}-S_{H}
$$

$R_{H_{\text {-- }}}$ The income of power grid enterprises before carry out direct power-purchase;

$R_{L}$-- After large user direct power-purchase, the income of power grid enterprises use remaining power supply the existing (or new) residents, agriculture and other low voltage user;

$S_{H}$-- The income of power grid enterprises provides direct power-purchase.

Considering the market efficiency and the different ability of classified user to bear electricity price, the government provides a part of the power grid enterprises loss beard by themselves. So can help to improve technology and management level, reduce cost, open source throttling, and improve the production efficiency of enterprises. The rest of the loss according to the specific power consumption allocate to large users who participate in direct power-purchase.

2) Take the form of the transmission and distribution price with cross-subsidization, the large user should be charged with the cost of cross subsidy in the price. First, stipulate large users according to their direct trading, per unit of electricity (kWh) to collect the corresponding cross subsidy costs, the fees within the prescribed period of time (such as 10 year) at a certain ratio (e.g., 10\%) decrease year by year until completely canceled. All the electricity provided by the power grid before large users involve in direct power-purchase. This past of the electricity, bought by power grid enterprises, weighted average purchase price can be expressed as the follow. $C_{w}=\sum_{i} p_{i} q_{i} / \sum_{i} q_{i}$

$C_{w}$-- A weighted average of their big users of electricity power purchase price (not including fuel and renewable energy units);

$p_{i}$-- The electricity price of the unit of the i unit, namely, the purchase price of the power grid enterprise;

$q_{i}$-- Corresponding power purchase.

After the large users participate in the direct powerpurchase, power grid enterprises will lose originally sold to large users of that part of the power of profits, based on this, cross-subsidization can be expressed as: 
$S_{c}=T_{i}-C_{w}(1+L)+W_{c}$

$S_{c_{--} \text {Cross-subsidization surcharge; }}$

$T_{i}$-- The electricity price before large users participate in the direct power-purchase

$L$-- Net loss rate of corresponding voltage grade;

$W_{c}$

$W_{c}$-- Basic transmission service charge.

By type (3-2), the average power consumption price of the power grid enterprise is calculated, which can reflect the cost of the unit electricity. Through the calculation, we can get the cross-subsidization surcharge, and compensate the loss of the power grid enterprise by the cross-subsidization.

3) Electricity generators, which are directly involved in the large users' direct power-purchase, should bear a part of cross-subsidization and the process is realized through the adjustment of the price of electricity. Power grid enterprises bear the cost of cross subsidy is achieved by reducing the cost of purchasing electricity and increasing the electricity price. Reduce the cost of power generation companies, who participate in direct powerpurchase, to a certain extent, to ensure the power grid enterprises purchase price, which is conducive to the power grid enterprises to assume the responsibility of cross-subsidization. And the reduction of electricity generation companies in the electricity price is essentially the cost of cross subsidies between the large user and power generation companies to a re allocation. When the electricity grid companies to pay for power generation enterprises, directly charge this part of the transaction cost of subsidies.

\section{Summary}

In conclusion, the government in the process of achieving l large users direct power-purchase crosssubsidization mechanism reform should be adheres to the principle of giving priority to efficiency, and fully considers the bear ability for electricity price of regional power producers and large users. While maintaining the existing sales price level, on the basis of increasing residential electricity, appropriate to reduce the electricity price for industrial users, so as to gradually reduce the cross-subsidization in the sales price, and ultimately the formation of no cross-subsidization, can reflect the true cost of electricity sales price. In this process, it should be noted that the purpose of cross subsidy mechanism is to protect the people's livelihood, cannot blindly price increases, the price of electricity can be adjusted by the lifeline tariff, that is, electricity consumption per person, per month is to be fixed in a certain standard, still by the current preferential tariff charges, beyond the prescribed scope of power except for its electricity charges can collect the right amount of electric power universal service fund, in the future when conditions are ripe, then gradually improve the electricity price for residents.

In addition, a reasonable and perfect power universal service mechanism is also essential: On the one hand, the government should formulate a fair, impartial and transparent universal service fund raising mechanism and management mechanism, and establish a scientific and reasonable universal service compensation mechanism. Let power grid enterprises play an important role in the social universal service, and to provide "fallback" services for key areas of cross-subsidization mechanism, that is to say, in the case of opening electricity market this area still enjoy certain preferential price, in order to achieve livelihood security and promote the development of the national economy; Power grid enterprises also actively carry out new technology, new equipment research, transformation of weak power grid, improve power grid structure and power supply reliability and quality, as far as possible to expand the network coverage, especially to solve the problem of the electricity the economic less-developed areas without electricity. Achieve the goal of providing affordable, nondiscriminatory electricity power supply service to all of the people.

\section{References}

[1] Frangioni, Antonio,Gentile, Claudio,Lacalandra, Fabrizio.Tighter approximated MILP formulations for unit commitment problems. IEEE Transactions on Power Systems . 2009

[2] James Ostrowski,Miguel F. Anjos,Anthony Vannelli.Tight Mixed Integer Linear Programming Formulations for the Unit Commitment Problem. IEEE Transactions on Power Systems . 2012

[3] Khodaei A,Shahidehpour M.Microgrid-based cooptimization of generation and transmission planning in power systems. IEEE Transactions on Power Systems . 2013 [1] J. van der Geer, J.A.J. Hanraads, R.A. Lupton, The art of writing a scientific article, J. Sci. Commun. 163 (2000) 51-59. 